Herzens und der Gefässe. Bromquecksilber wirkte ungefähr wie das Chlorquecksilber bel gleichen Gaben.

Nach B onnet verdienen die Bromquecksilber-Verbindungen dem Calomel und Sublimat vorgezogen zu werden, weil sie weniger auf die Speicheldrüsen und mehr auf den Urin wirken; was auch von" $M$ a g e ndie und Willi a m s beobachtet worden ist. (Repert. f. d. Pharm. 2te $R$. Bd.43. H.3.) $B$.

\title{
Einige neue und seltene Arten von thierischen Concretionen.
}

Harnsteine des Leguana. In der Sammlung von Harnsteinen des Royal College of Surgeons finden sich drei Steine, welche grosse Aehnlichkeit mit einander haben und die von Th. Taylor untersucht worden sind. Zwei davon waren als die Harnsteine eines Leguana bezeichnet, der dritte war unbezeichnet, hatte jedoch dieselbe chemische Zusammensetzung. Aeusserlich glichen die Concretionen den sogenannten schmelzbaren Harnsteinen, innerlich zeigten sie schmutzig-weisse concentrische Schichten. Sie waren eiförmig, aber an der einen Seite etwas abgeflacht. Die Analyse ergab:

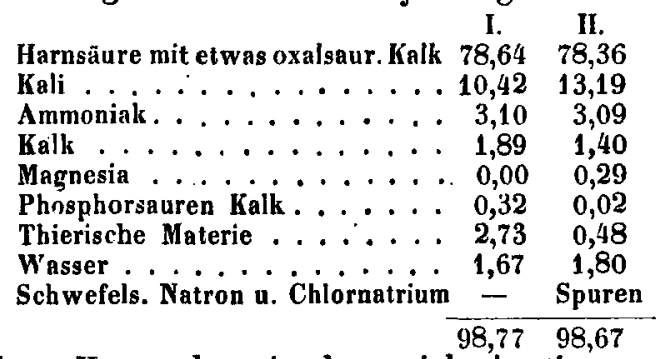

Analyse II. wurde mit dem nicht bestimmten Steine angestellt. Der Kaligehalt ist wohl von den Blättern herzuleiten, welche die hauptsächlichste Nahrung des Leguana ausmachen; die Harnsäure grösstentheils von den Insekten, welche dieses Thier verzehrt.

Harnsteine des Hausens (sogenannte Belugensteine). Diese werden nach Pallas in den erweiterten Ureteren oder der Cloake des Hausens (Acipenser Huso L.) gefunden. Sie sind gewöhnlich flach, eiförmig, im Centrum oft mit einem flachen Eindrucke versehen. Die Grösse ist sehr verschieden, gewöhnlich wie ein Hühnerei. Die Oberfläche derselben ist glatt und gelblich - weiss. Auf dem Bruche zeigen sie eine krystallinische concep- 
Neue und sellene Arten von thierischen Concretionen.

trisch-strahlige Structur. Die Steine sind äusserst rar und wurden früher als Medicamente hochgeschälzt. T a ylor's Analyse ergab:

$\begin{array}{lrr}\text { Wasser . . . . . } & 26,33 & 25,60 \\ \text { Organische Materie. } & 0,40 & 1,13 \\ \text { Phosphorstaren Kalk } & 73,27 & 73,27\end{array}$

Darmconcretionen. Diese theilt Taylor in neun verschiedene Arten ein. 1) Concretionen aus thierischen Haaren; 2) Concretionen aus vegetabilischen Haaren; 3) aus Ellagsäure; 4) aus Lithofellinsäure; 5) aus phosphorsauner Ammoniak - Magnesia; 6) aus phosphorsaure! Magnesia; 7) aus phosphorsaurem Kalk ; 8) aus oxalsaurem Kalk; 9) aus Ambra.

Aus den von Taylor mit diesen Concretionen angestellten Versuchen ergiebt sich, dass der Hauptbestandtheil der Concretionen aus Lithofellinsäure ein vegetabilisches, krystallisirbares Harz ist, welches von einer geringen Menge eines weichen Harzes begleitet ist. Gallenfarbstoff, welchen Göbel darin gefunden hat, liess sich niemals nachweisen; übrigens könnte auch das Vorkommen desselben, welches nur zufallig sein würde, nicht als Beweis dafür dienen, dass jene Concretionen Gallensteine wären, da man Gallenfarbstoff auch in den Haarballen und anderen Darmconcretionen findet.

Die reine Harz-Bezoarsäure gab in der Analyse:
C. Taylor.
Eutling u. Will.
Wöhler.
H. 10,71
71,99
70,80
70,83
0. 18,58
10,85
10,78
10,60
18,57
71,00

Bekanntlich hat die Säure nach Ettling und Will die Formel: $\mathrm{C}^{4}{ }^{2} \mathrm{H}^{74} \mathrm{O}^{14}+\mathrm{H}^{2} \mathrm{O}$, nach Wöhler: $\mathrm{C}^{4}{ }^{6} \mathrm{H}^{7}{ }^{\circ} \mathrm{O}^{7}$ $+\mathrm{H}^{2} \mathrm{O}$.

Taylor hat friher die obigen Concretionen unter dem Namen der ächten occidentalischen Bezoare beschrieben; allein er glaubt jetzt, dass die ächten occidentalischen Bezoare, welche aus Suidamerika kommen, aus basisch phosphorsaurem Kalk bestehen, und dass die Concretionen, welche als Lapis Bezoar occidentalis aus Persien kommen, nur wegen des ähnlichen äussern Ansehens so genannt werden. (Phil.Mag. and Journ. of Science. Vol.28. - Pharm. Centralbl. 1846. No. 32.) B. 